\title{
Deafening Alters Neuron Turnover within the Telencephalic Motor Pathway for Song Control in Adult Zebra Finches
}

\author{
Niangui Wang, Rina Aviram, and John R. Kirn \\ Department of Biology, Wesleyan University, Middletown, Connecticut 06459
}

In the telencephalon of adult songbirds, projection neurons are lost and replaced within the efferent pathway controlling learned vocal behavior. We examined the potential role of auditory experience in regulating the addition and long-term survival of vocal control neurons in adult male zebra finches. Deafened and control birds were injected with the cell birth marker $\left[{ }^{3} \mathrm{H}\right]$ thymidine and then killed 1 or 4 months later. At the 1 month survival time, the number of $\left[{ }^{3} \mathrm{H}\right]$-labeled neurons present in the high vocal center (HVC) was $70 \%$ lower in deafened birds compared with controls. This was true for all $\left[{ }^{3} \mathrm{H}\right]$-labeled HVC neurons, as well as the subset that projected to the robust nucleus of the archistriatum. Over the next 3 months, two-thirds of the $\left[{ }^{3} \mathrm{H}\right]$-labeled HVC neurons in control birds were lost, presumably through cell death. Surprisingly, deafened birds showed no loss over this interval. The total number of HVC neurons did not differ between control and deafened birds at either survival time. Nuclear diameters of $\left[{ }^{3} \mathrm{H}\right]$-labeled HVC neurons decreased with cell age in both control and deafened birds, a process that may relate to the eventual death and replacement of these cells. These results suggest that experience influences the addition and also the longer-term fate of neurons formed in adulthood. We propose that auditory deprivation decreases the incorporation of new neurons and prolongs their life span. Alterations in the neuronal replacement cycle may relate to the gradual deterioration in song that occurs after deafening in adult zebra finches.

Key words: adult neurogenesis; auditory experience; nuclear size; neuronal life span; zebra finch; high vocal center; $\left[{ }^{3} \mathrm{H}\right]$ thymidine autoradiography
Neurogenesis occurs in several adult warm-blooded vertebrates, including humans (Eriksson et al., 1998). Delineating the functions and control of neurogenesis in otherwise mature animals has potential significance for both brain repair and understanding normal brain function. Songbirds provide an exceptional model for addressing these issues. The most widespread adult neurogenesis occurs in birds in which neurons are added throughout much of the telencephalon (Alvarez-Buylla and Kirn, 1997; Goldman, 1998). Moreover, many adult-formed neurons are inserted into discrete neural circuits controlling song, a well characterized, learned behavior.

Adult-formed neurons are incorporated into the high vocal center (HVC), a telencephalic region necessary for song perception and production (Nottebohm et al., 1976; Simpson and Vicario, 1990; Brenowitz, 1991). Many of these cells send an axon 2-3 mm to the robust nucleus of the archistriatum (RA), another nucleus essential for song production (Nordeen and Nordeen, 1988; Alvarez-Buylla et al., 1990a). In adult canaries, these neurons can live for 8 months or longer (Kirn et al., 1991; Nottebohm et al., 1994). However, most adult-formed HVC neurons eventually die and are then replaced (Nottebohm, 1985; Alvarez-Buylla and Kirn, 1997).

Previous work suggests that HVC neuronal replacement may

\footnotetext{
Received June 7, 1999; revised Sept. 21, 1999; accepted Sept. 21, 1999.

This work was supported by Public Health Service Grant NS29843 and the Scott Family Charitable Trust. We thank Ann Hesla for technical assistance. Poornima Tekumalla, John Dekker, and two anonymous reviewers provided helpf ul comments on earlier drafts of this manuscript.

Correspondence should be addressed to Niangui Wang, Biology Department, Wesleyan University, Hall Atwater and Shanklin Labs, Middletown, CT 06459. E-mail: nwang@mail.wesleyan.edu.

Copyright (C) 1999 Society for Neuroscience 0270-6474/99/1910554-08\$05.00/0
}

be important for song plasticity. In adult canaries, HVC neuronal turnover is highest at times of year when males learn new songs. However, neuronal replacement also occurs, albeit at low rates, in adult canaries when song modification is minimal and in male zebra finches, which normally do not change their songs in adulthood (Nordeen and Nordeen, 1988; Alvarez-Buylla et al., 1990a; Kirn et al., 1994).

As a further step toward understanding adult neurogenesis and its relationship to behavior, we examined the effects of deafening on HVC neuronal replacement and song in adult zebra finches. Song relies on auditory input in several songbird species (Brenowitz et al., 1997). For example, zebra finches deafened as juveniles fail to development normal song (Price, 1979), and deafening in adulthood leads to a gradual deterioration in song structure (Nordeen and Nordeen, 1992). HVC neurons, including adult-formed neurons, respond to auditory stimuli (Paton and Nottebohm, 1984), and auditory activity is transferred to RA by the RA-projecting neurons of the HVC (Doupe and Konishi, 1991; Vicario and Yohay, 1993). Thus, auditory experience might play an especially important role in the regulation of RAprojecting $\mathrm{HVC}$ neuron addition and survival.

Experience has been shown to influence postnatal neuron addition in other systems (Brunjes, 1994; Clayton and Krebs, 1994; Gould et al., 1999; van Praag et al., 1999). Interestingly, auditory input is not necessary for neuronal addition in young zebra finches (Burek et al., 1991). However, we know of no previous studies that have asked how experience affects the incorporation and subsequent fate of adult-formed neurons once they have been integrated into the brain. Therefore, we measured the effect of deafening in adulthood on the incorporation and long-term survival of a cohort of HVC neurons labeled by 
$\left[{ }^{3} \mathrm{H}\right]$ thymidine injections. We show that auditory input is essential for the normal cell replacement cycle in ways that may relate to song motor control.

\section{MATERIALS AND METHODS}

All animal experimentation conformed to National Institutes of Health guidelines and was approved in advance by the Institutional Animal Care and Use Committee at Wesleyan University. Birds were obtained from our breeding colony or were purchased from Canary Bird Farm (Old Bridge, $\mathrm{NJ})$. Wesleyan birds $(n=23)$ ranged in age from 5 to 24 months, with the exception of 1 bird that was 36 months old. This age range was the same in all experimental groups. We are less certain of the age of Canary Bird Farm birds $(n=9)$. However, based on the presence of mature male plumage and beak coloration at the time of purchase, plus the time spent in our facility before this study, these birds were at least 4-5 months old at the beginning of the study. Three of the four experimental groups received two of these birds each, and the 4 month survival deafened group received three of these birds. Birds were housed on a $14 / 10 \mathrm{hr}$ light $/$ dark cycle at $22^{\circ} \mathrm{C}$. Seed and water were available ad libitum and were supplemented with a mixture of cooked eggs and baby cereal every 2-3 d. Deafened and control birds were kept together in groups of two to five per cage throughout the experiment.

Behavioral analyses. The effects of deafening on adult zebra finch song have been described in detail previously (Nordeen and Nordeen, 1992), and so we did not originally plan a systematic behavioral analysis in the present study. However, we recorded song in some of our birds to ensure that deafening resulted in song changes. Our experiments were done in two replications, and the birds in the second replication were used for behavioral analyses. Song was recorded at three time points: no more than 2 weeks before deafening, 4-5 weeks (short- and long-survival groups; $n=5$ controls; $n=5$ deafened), and 16-17 weeks (long-survival groups only; $n=3$ controls; $n=3$ deafened) postoperatively. Recordings were made in a sound-attenuating chamber using a condenser cardioid microphone (Electro-Voice, Inc., Buchanan, MI) and Marantz PMD 222 cassette tape recorder. Females were present during all recording sessions to stimulate song production. Zebra finch songs typically begin with several repetitions of the same short introductory note followed by a series of several acoustically distinct notes or syllables that are repeated in a regular sequence called a motif. A motif is often repeated a variable number of times before a song bout ends, and introductory notes plus these motif repetitions are collectively referred to as a song strophe (Hall, 1962; Sossinka and Bohner, 1980). At each recording date, several motifs (mean of 26) and strophes (mean of 9) were recorded for each bird. For detailed analysis, sonograms were first digitized at a sampling rate of $22050 \mathrm{~Hz}$ using Canary 1.2 software (Cornell Bioacoustics Laboratory, Ithaca, NY) on a Power Macintosh 7500 computer (Apple Computers, Cupertino, CA). The average note duration and internote interval were measured from the time-frequency envelope on the sonogram. The latter measure was found to be sensitive to the effects of deafening in previous work (Nordeen and Nordeen, 1992). Notes were defined as continuous traces separated from one another by silent intervals. A strophe was considered complete if followed by $0.5 \mathrm{sec}$ or more of silence. Internote intervals were measured from the end of one note to the beginning of the next note. These measures were taken for all notes and intervals within a strophe and averaged across a minimum of three motifs and two strophes for each bird.

Bilateral cochlea removal. Bilateral cochlea removal was performed following the procedure of Konishi (1964) with slight modification. Birds were deeply anesthetized with intramuscular (pectoral) injections of ketamine (Ketaset; 0.025-0.040 ml/bird, $100 \mathrm{mg} / \mathrm{ml}$; Parke-Davis, Fort Dodge, IA) and xylazine $(0.025-0.040 \mathrm{ml} / \mathrm{bird}, 20 \mathrm{mg} / \mathrm{ml}$; The Butler Co., Columbus, $\mathrm{OH}$ ). Feathers were plucked from a region behind the ears caudally to the median line on both sides. This region was then sterilized with $70 \%$ ethanol, and an incision was made through the skin and other soft tissues from the rear rim of the ear to the median line of the occipital portion of the skull. The muscles overlying the mastoid region were retracted, and superficial bone was ruptured with a pair of fine forceps. The bony canal encasing the cochlea and posterior and external semicircular canals could then be seen clearly, and a small hole was made through the proximal end of the bony cochlea with fine forceps. A fine rigid wire hook was inserted through the small hole to grasp the proximal end of the cochlea, and the cochlea was then removed. The extracted cochlea was inspected for the presence of an intact lagena (the distal part of the cochlea), confirming complete cochlea removal. The bony flaps of the cranium and the muscles of the scalp were then returned to their original position, and the skin incision was closed with surgical tape. These procedures were then repeated on the contralateral side. After surgery, birds were placed in an incubator to facilitate recovery and then returned to their home cages. In our hands, this surgical method was preferred over one in which the approach is made via the external meatus because the latter tended to be associated with more bleeding and excessive vestibular disturbances. Two types of control procedures were used. Five control birds (two in the short-survival group and three in the long-survival group) experienced all of the surgical steps described above, including removal of superficial skull overlying the bony canal encasing the cochlea, but the cochlea was not touched. Eleven other control birds were unoperated (six short-survival and five long-survival). We found no systematic differences in the data derived from the two control procedures, and so data were pooled. For example, total $\left[{ }^{3} \mathrm{H}\right]-$ labeled $\mathrm{HVC}$ neuron numbers in unoperated short-survival birds ranged from 275 to 1585 , whereas in operated controls, labeled cell numbers ranged from 248 to 976 . Three of the six unoperated birds had values lower than the highest value for operated birds. At 4 month survivals, unoperated controls had 91 to 576 such cells compared with 200 to 597 for operated controls.

$\left[{ }^{3} H\right]$ Thymidine injections. Two to 3 weeks after surgery, all birds received intramuscular (pectoral muscles) injections of $\left[{ }^{3} \mathrm{H}\right]$ thymidine (methyl- $\left[{ }^{3} \mathrm{H}\right]$ thymidine, $2.5 \mu \mathrm{Ci} / \mathrm{g} ; 6.7 \mathrm{Ci} / \mathrm{mmol} ; 1 \mathrm{Ci}=37 \mathrm{GBq} ; \mathrm{NEN}$, Boston, MA), every $12 \mathrm{hr}$ (8:00 A.M. and 8:00 P.M.) for 4 consecutive days to label dividing cells (Sidman, 1970; Goldman and Nottebohm, 1983). A delay of $2-3$ weeks between deafening and $\left[{ }^{3} \mathrm{H}\right]$ thymidine injections was chosen to minimize potential nonspecific effects of surgery. Deafened birds were able to perch and fly within $24 \mathrm{hr}$ after surgery. The interval between surgery and $\left[{ }^{3} \mathrm{H}\right]$ thymidine treatment was similar for 1 and 4 month survival groups (mean of $16 \mathrm{~d}$, range of 13-21 $\mathrm{d}$ for short-survival birds; mean of $18 \mathrm{~d}$, range of 13-24 $\mathrm{d}$ for longsurvival birds).

Fluoro-Gold labeling. Four days before being killed, Fluoro-Gold (2hydroxy-4,4'-diamidinostilbene; Fluorochrome Inc., Engelwood, CO.) was injected into RA bilaterally to retrogradely label RA-projecting HVC neurons as described previously (Alvarez-Buylla et al., 1990a; Kirn et al., 1991; Kirn and Schwabl, 1997). Birds were anesthetized as for deafening. They were then placed in a stereotaxic instrument, a midline scalp incision was made, and the soft tissues over the dorsal skull surface were retracted. The skull was cleaned with $0.1 \mathrm{M}$ PBS, and a small patch of skull and dura was removed to expose the brain overlying injection sites. Fluoro-Gold [2\% (w/v) in $0.9 \%(\mathrm{w} / \mathrm{v})$ saline] was pressure-injected into RA at a $10^{\circ}$ angle from vertical using glass micropipettes (inner tip diameter of 20-25 $\mu \mathrm{m}$ ). Injections were made at four different sites in each hemisphere $(10-20 \mathrm{nl} /$ injection) to produce maximal retrograde labeling of RA-projecting HVC neurons (Fig. 1A). The micropipette was then withdrawn, and the incision was closed with surgical tape. Animals were allowed to recover in an incubator and then returned to their home cages. In all birds, injection sites encompassed $50-100 \%$ of RA and usually encroached on surrounding archistriatum. Previous work has shown that quantitatively similar patterns of HVC labeling can occur, despite such targeting variation (Kirn et al., 1991; Kirn and Nottebohm, 1993), perhaps because terminal fields within RA for HVC neuronal axons are extensive and there is no topographic relationship between HVC and RA (Vicario and Simpson, 1988; Vicario, 1994).

Survival time, perfusion, and fixation. Eight deafened and eight control birds were killed $28 \mathrm{~d}$ after the last $\left[{ }^{3} \mathrm{H}\right]$ thymidine injection to measure the initial incorporation of neurons born at the time of $\left[{ }^{3} \mathrm{H}\right]$ thymidine injections. The $28 \mathrm{~d}$ survival time was chosen based on the following information. New neurons arrive and begin to differentiate in HVC as early as 1 week after their formation (Burek et al., 1991; Kirn et al., 1999). However, it takes $\sim 3$ weeks for such cells to acquire their adult phenotype and send axons to RA (Burd and Nottebohm, 1985; AlvarezBuylla and Nottebohm, 1988; Kirn et al., 1999). We reasoned that, by 4 weeks, most if not all neurons born at the time of $\left[{ }^{3} \mathrm{H}\right]$ thymidine injections would have arrived in HVC. The remaining birds $(n=16,8$ per group) were killed $120 \mathrm{~d}$ after cell birth-dating to follow the subsequent survival of the $\left[{ }^{3} \mathrm{H}\right]$ thymidine-labeled neurons. Earlier work, using 1 and 4 month survivals after $\left[{ }^{3} \mathrm{H}\right]$ thymidine injections, had shown that this paradigm was sufficient to reveal seasonal differences in the survival of adult-formed HVC neurons in canaries (Nottebohm et al., 1994). Within the framework of temporal changes in zebra finch song after deafening in adulthood, Nordeen and Nordeen (1992) reported that the earliest consistent song changes occurred by $\sim 6$ weeks after deafening, 

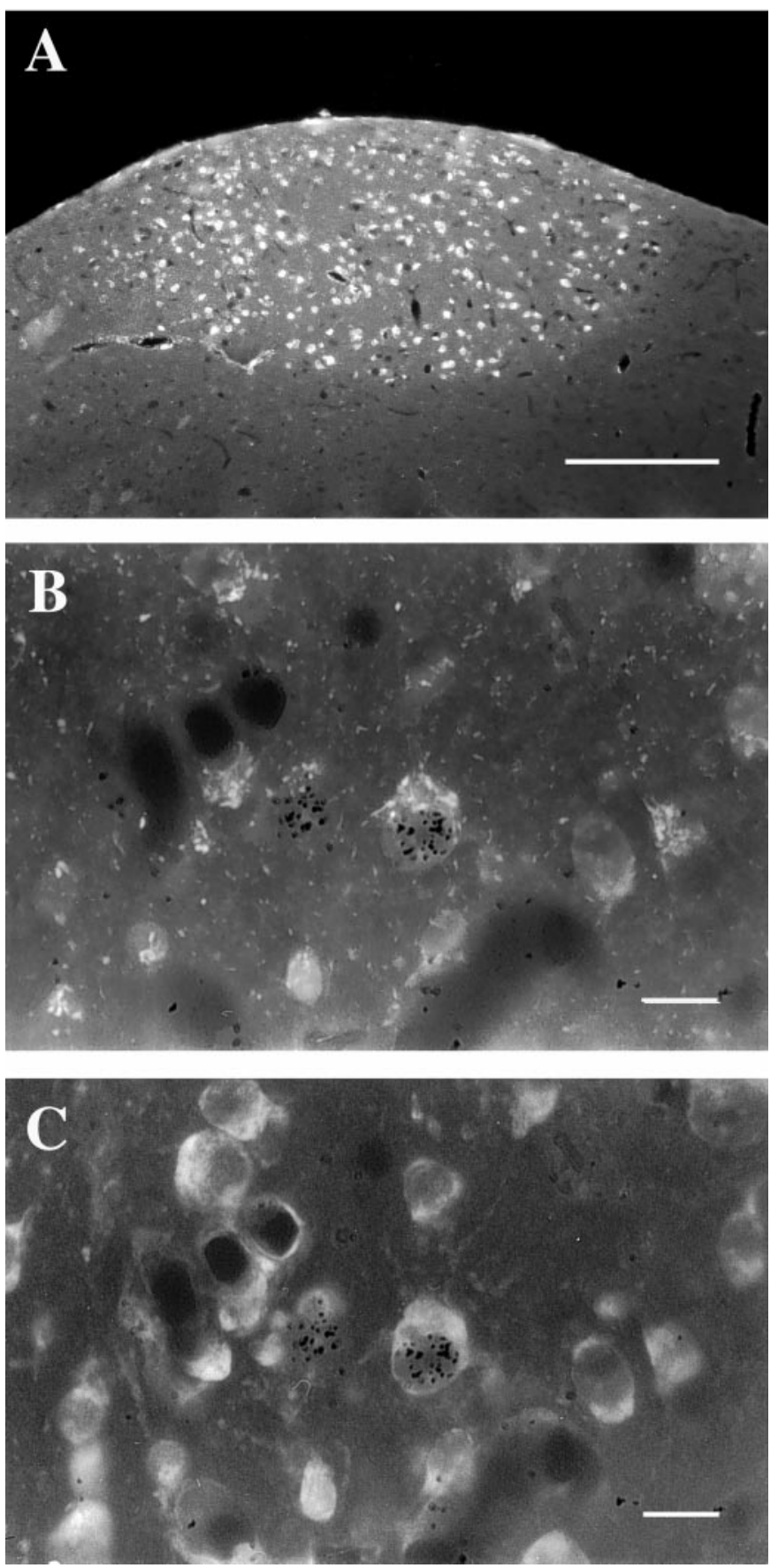

Figure 1. A, Low-magnification fluorescence (UV) photomicrograph of a $6 \mu \mathrm{m}$ parasagittal $\mathrm{HVC}$ section. Over half of all $\mathrm{HVC}$ neurons project to RA, and when these cells are retrogradely labeled by Fluoro-Gold (white), HVC clearly stands out from surrounding areas. Dorsal is up, and caudal is to the left. The hippocampus, which normally overlies HVC, was lost during tissue processing. $B, C$, Higher power combined fluorescencebright-field photomicrographs of the same field viewed with different fluorescence filters. In $B$, exposed silver grains (black) overlying the nucleus of two cells indicate that these cells were produced at or shortly after injections of $\left[{ }^{3} \mathrm{H}\right]$ thymidine. One of these cells (right) also contains Fluoro-Gold in the cytoplasm (whitish stipple) when visualized with UV fluorescence, indicating that it was an adult-formed RA-projecting HVC neuron. In $C$, the same field is viewed with rhodamine fluorescence to show all cells counterstained with fluorescent cresyl violet. The $\left[{ }^{3} \mathrm{H}\right]-$ labeled cell on the left is not easily discernable in $C$ because it is not in the same focal plane as the silver grains overlying its nucleus. Scale bars: $A$, $200 \mu \mathrm{m} ; B, C, 10 \mu \mathrm{m}$. and by 4 months, song patterns were significantly deteriorated in most birds.

Birds were deeply anesthetized by inhalation of methoxyflurane (Metofane; Mallinckrodt Inc., Mundelgn, IL) and then quickly perfused via the left ventricle with $20-30 \mathrm{ml}$ of $0.1 \mathrm{M}$ PBS, $\mathrm{pH} 7.4$, followed by paraformaldehyde [ $40-50 \mathrm{ml}$ of $4.0 \%(\mathrm{w} / \mathrm{v})$ in $0.1 \mathrm{M}$ PBS, $\mathrm{pH}$ 7.4]. The brains were removed, stored in the same fixative for 3-5 d, and embedded in polyethylene glycol (Polysciences, Warrington, PA) (Smithson et al., 1983; Clayton and Alvarez-Buylla, 1989). Sagittal brain sections containing $\mathrm{HVC}$ were cut at a thickness of $6 \mu \mathrm{m}$ on a rotary microtome, and every eighth section was mounted onto precleaned, chrom-alum-subbed slides and air-dried. Then sections were delipidized with an ascending series of ethanol washes and cleared in xylene. The sections were then rehydrated and stored in a dust-free oven overnight.

Autoradiography and counterstaining. Slides were dipped in nuclear track emulsion (NTB2; Eastman Kodak, Rochester, NY) in a $37^{\circ} \mathrm{C}$ water bath and allowed to dry at $37^{\circ} \mathrm{C}$ in a light-tight oven for $3 \mathrm{hr}$. Slides were then boxed with desiccant and stored at $4^{\circ} \mathrm{C}$ for $28 \mathrm{~d}$. Slides were then processed in Kodak D-19 developer for $3 \mathrm{~min}$ at $17^{\circ} \mathrm{C}$, tap water at $19^{\circ} \mathrm{C}$ for $1 \mathrm{~min}$, Kodak standard fixer at $19^{\circ} \mathrm{C}$ for $12 \mathrm{~min}$, and running tap water for 10-20 min. Then, sections were counterstained through the emulsion with fluorescent cresyl violet, which allows morphological identification of all cells but preserves the Fluoro-Gold fluorescence (Fig. 1B,C) (Alvarez-Buylla et al., 1990b). Finally, the sections were dehydrated through graded ethanols, cleared in xylene, and coverslipped with Krystalon (Harleco; EM Science, Gibbstown, NJ).

Microscopic analysis. All slides were coded before microscopic analysis, and the codes were not disclosed until data collection was complete. Area measurements and cell counting were performed using 10 and $100 \times$ objectives on a computer-yoked fluorescence microscope system (Alvarez-Buylla and Vicario, 1988). The Fluoro-Gold labeling was visualized using UV fluorescence (Fig. $1 A$ ); $\left[{ }^{3} \mathrm{H}\right]$ labeling was identified with bright-field optics (Fig. $1 B, C$ ), and the fluorescent cresyl violet counterstain was visualized with rhodamine fluorescence (Fig. $1 C$ ). Fluoro-Gold labeling enabled identification of RA-projecting HVC neurons. Cells not labeled by Fluoro-Gold were classified as neurons based on their size and pattern of Nissl staining with fluorescent cresyl violet. Cells classified as neurons had a relatively large, clear nucleus and 1-2 darkly stained nucleoli. These criteria have been validated in ultrastructural work (Burd and Nottebohm, 1985) and by retrograde labeling (Alvarez-Buylla et al., 1990a; Kirn et al., 1991; Kirn and Nottebohm, 1993; Nottebohm et al., 1994). A neuron was recognized as $\left[{ }^{3} \mathrm{H}\right]$-labeled when the number of exposed silver grains overlying the nucleus was at least 20 times that of the surrounding neuropil; in our material, this corresponded to at least seven exposed silver grains over the nucleus of a cell.

All neuronal attributes described were calculated unilaterally based on Fluoro-Gold labeling intensity. Previous work has failed to detect any systematic left-right differences in adult neuron addition (Nottebohm et al., 1994). In each bird, HVC perimeters, as defined by the Fluoro-Gold backfills (Fig. $1 A$ ), were traced in 10 equally spaced sections, and the cross-sectional area of $\mathrm{HVC}$ was calculated for each section. HVC volume for each bird was estimated by multiplying area measurements by section thickness and sampling interval (Kirn et al., 1991; Kirn and Schwabl, 1997). HVC in these sections was completely scanned for $\left[{ }^{3} \mathrm{H}\right]$ thymidine-labeled neurons. All HVC neurons and all Fluoro-Goldlabeled neurons were counted in four equally spaced sections. The number of cells per volume sampled in each cell class was multiplied by HVC volume to get estimates of total cell number. Nuclear diameters were measured for all $\left[{ }^{3} \mathrm{H}\right]$-labeled neurons encountered and for 30 Fluoro-Gold-labeled and 30 non-Fluoro-Gold-labeled neurons in each bird. Previous work suggests that cell nuclear size changes of the magnitude encountered here are not likely to bias estimates of neuron number derived from $6 \mu \mathrm{m}$ sections (Clark et al., 1990). Therefore, no corrections were made for cell splitting because we were primarily interested in relative group differences in neuronal number. None of the parameters measured in this study varied systemically with the source of the birds, the ages of birds at the time of deafening, or the interval between deafening and $\left[{ }^{3} \mathrm{H}\right]$ thymidine injections.

Statistical analysis. Final sample sizes were $n=8$ for each group. All data are presented as group means \pm SEM. Statistical comparisons of neuronal attributes were conducted using two-way ANOVA with the independent factors being treatment and survival time. Planned, pairwise comparisons were conducted using one-way ANOVA. Song analyses were restricted to between-group comparisons at each recording time. A complete, within-subjects analysis was not warranted because it 
would omit all data for birds that were killed before the 4 month recordings.

\section{RESULTS}

\section{Effects of deafening on neuronal attributes}

HVC volume (as defined by Fluoro-Gold backfills from RA), the total number of HVC neurons, and the total number of FluoroGold-labeled neurons as a function of treatment and survival time are summarized in Figure $2 A-C$. There was a trend toward smaller HVC volumes (as defined by Fluoro-Gold backfills from RA) in deafened birds compared with controls, irrespective of survival time (Fig. 2A). However, these differences did not reach statistical significance $(p=0.07$ for 1 month survival; $p=0.31$ for 4 month survival). HVC volumes did not change markedly between survival times in either control or deafened birds $(p>0.30)$.

The total number of HVC neurons (Fig. 2B) and the subset that were Fluoro-Gold-labeled (Fig. 2C) were not significantly different between control and deafened birds, although group differences approached significance at the shorter survival time ( $p=0.07$ and 0.11 for total neurons and total Fluoro-Goldlabeled neurons, respectively, at 1 month survival; $p>0.5$ for 4 month survival). Between survival times, the total number of HVC neurons and the number labeled by Fluoro-Gold were also relatively stable for control and deafened groups $(p>0.2$ for all comparisons).

In contrast, there were dramatic effects of deafening on the cohort of HVC neurons labeled by $\left[{ }^{3} \mathrm{H}\right]$ thymidine (Fig. $3 A, B$ ). Twenty-eight days after $\left[{ }^{3} \mathrm{H}\right]$ thymidine injections, control birds had nearly four times more $\left[{ }^{3} \mathrm{H}\right]$-labeled $\mathrm{HVC}$ neurons than deafened birds $(p=0.004)$. Many of the adult-formed HVC neurons were retrogradely labeled by Fluoro-Gold injections into RA in deafened and control birds. However, substantially fewer new RA-projecting HVC neurons were found in deafened birds compared with controls (Fig. $3 B)(p=0$.016).

Paradoxically, 4 months after $\left[{ }^{3} \mathrm{H}\right]$ thymidine injections, there were no differences between control and deafened groups in the total number of $\left[{ }^{3} \mathrm{H}\right]$-labeled $\mathrm{HVC}$ neurons or $\left[{ }^{3} \mathrm{H}\right]$-Fluoro-Gold labeled cells (Fig. $3 A, B)(p>0.3)$. Comparisons between the two survival times indicated that control birds showed a considerable decrease over this interval in both the total number of $\left[{ }^{3} \mathrm{H}\right]$ thymidine-labeled HVC neurons $(p=0.009)$ and the number of these cells labeled by Fluoro-Gold ( $p=0.034)$. In contrast, when we did the same analyses for the deafened birds, no changes were found between the 1 and 4 month survival periods $(p>0.3)$.

The mean \pm SEM nuclear sizes of different classes of HVC neurons are summarized in Table 1 . The nuclear diameters of the $\left[{ }^{3} \mathrm{H}\right]$ thymidine-labeled HVC neurons became smaller between 1 and 4 month survival times. Similar results were obtained for the nuclear diameters of $\left[{ }^{3} \mathrm{H}\right]$-labeled neurons, regardless of whether they were also Fluoro-Gold-labeled or not $(p<0.0001)$. Deafened birds did not differ from control birds on any of these measures of nuclear diameter $(p>0.27)$. To determine whether nuclear size changes were specific to the cohort of HVC neurons labeled by $\left[{ }^{3} \mathrm{H}\right]$ thymidine, we also measured the nuclear diameters of HVC neurons more generally in all four groups of animals. HVC neuronal nuclear sizes did not differ as a function of survival time or treatment group ( $p \geq 0.12$ ). However, the size of Fluoro-Gold-labeled HVC neurons tended to be smaller in deafened birds compared with controls at the 4 month survival time, and this difference approached statistical significance $(p=0.07)$.
A
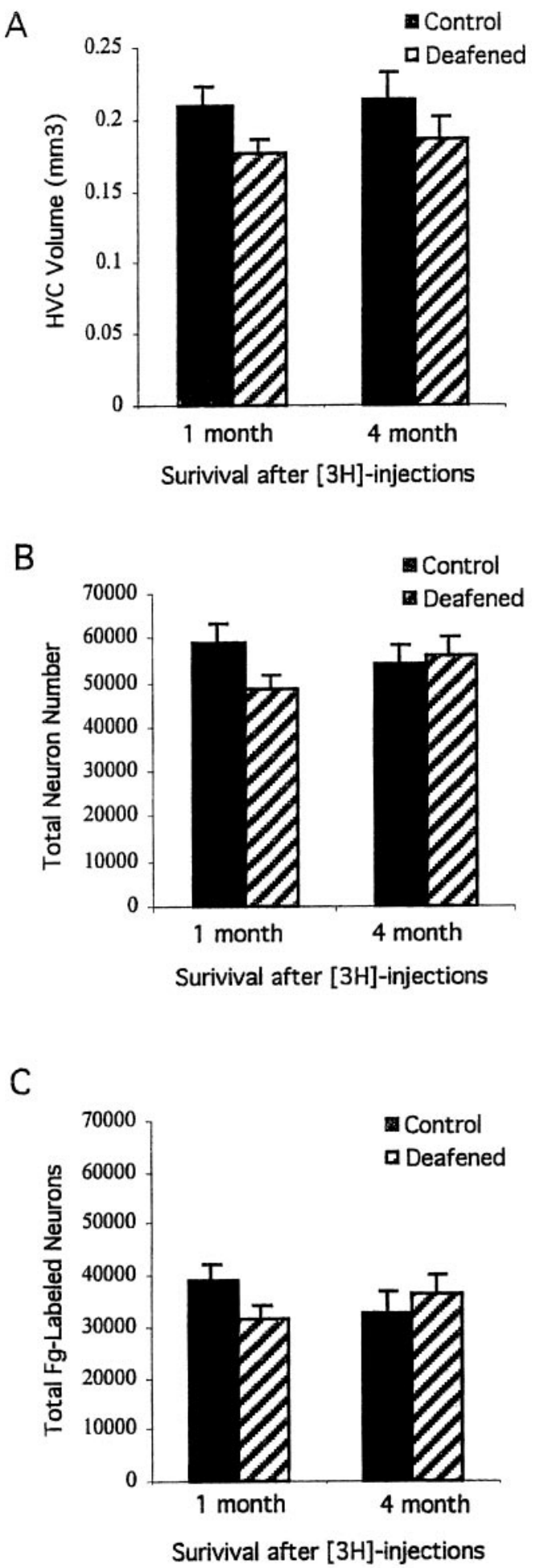

Figure 2. Mean \pm SEM estimates of HVC volume $(A)$, total neuron number $(B)$, and total number of RA-projecting HVC neurons $(C)$ as defined by Fluoro-Gold $(\mathrm{Fg})$ backfills from RA. Two to 3 weeks after deafening in adulthood, experimental birds and controls were injected with $\left[{ }^{3} \mathrm{H}\right]$ thymidine and then killed either 1 or 4 months after the last injection. No significant differences were found on any of these measures between deafened and control birds. 

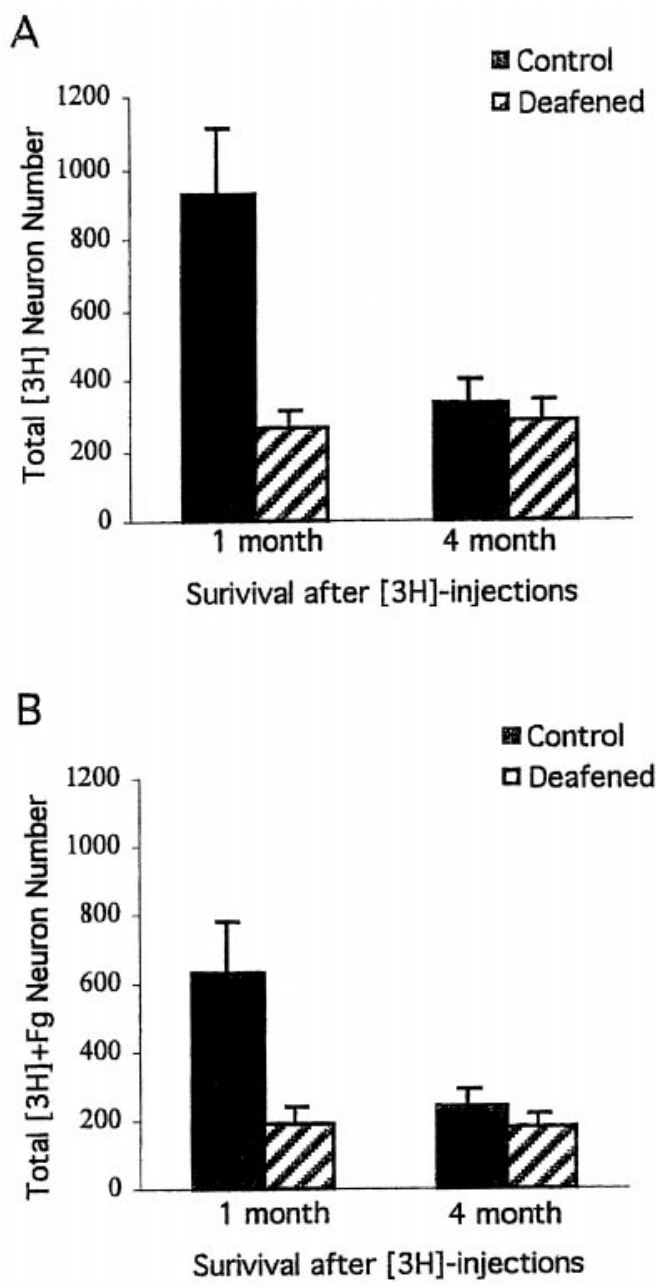

Figure 3. Mean \pm SEM estimates of the total number of new HVC neurons $\left(\left[{ }^{3} H\right]\right)$ and new RA-projecting HVC neurons $\left.\left({ }^{3} H\right]+F g\right)$ at two survival times after $\left[{ }^{3} \mathrm{H}\right]$ thymidine injections. The 1 month survival time was designed to measure the effects of deafening on HVC neuronal incorporation. Comparisons between the 1 and 4 month survival times permitted an analysis of the subsequent survival of these cells. There was a dramatic difference between deafened and control birds in the total number of new HVC neurons $(p=0.004)$ and the fraction that projected to RA, as defined by Fluoro-Gold $(\mathrm{Fg})$ backfills from RA, at the 1 month survival time $(p<0.016)$. In contrast, there were no significant group differences at the 4 month survival time. This was because of a significant decrease in total new HVC neurons and new RA-projecting cells in control $(p<0.04)$ but not deafened birds $(p>0.3)$ between the two survival times.

\section{Effects of deafening on song}

Consistent with previous work (Nordeen and Nordeen, 1992), song deteriorated progressively with time after deafening in adulthood. Sonograms of the preoperative and 4-monthpostoperative songs produced by one control and one deafened bird are shown in Figure 4. In contrast to hearing birds, deafened birds showed a pronounced breakdown in the harmonic structure of notes, particularly at the longest survival time. Average note durations and internote intervals are summarized in Table 2. Deafening was associated with a gradual shortening of note length. There were no group differences in preoperative note durations $(p=0.75)$. Note that durations tended to be shorter in some deafened birds compared with controls as early as the 1 month postoperative recording time; however, overall group dif- ferences did not reach statistical significance until the next recording date 3 months later ( $p=0.09$ for 1 month; $p=0.002$ for 4 month recordings). Deafening was also associated with an increase in the duration of internote intervals, and this effect reached statistical significance by the 1 month recording date and remained marginally significant at the longer recording date $(p=$ 0.48 for preoperative song; $p=0.05$ for 1 month; $p=0.06$ for 4 months).

\section{DISCUSSION}

We found that deafening had dramatic effects on the incorporation of new HVC neurons in adult male zebra finches. One month after $\left[{ }^{3} \mathrm{H}\right]$ thymidine injections, the number of $\left[{ }^{3} \mathrm{H}\right]$-labeled $\mathrm{HVC}$ neurons, including new RA-projecting cells, in deafened birds was only one-fourth that of controls.

However, comparisons of 1 and 4 month survivals suggest that experience affects the fate of new neurons in complex ways. In control birds, over two-thirds of the $\left[{ }^{3} \mathrm{H}\right]$-labeled neurons present in $\mathrm{HVC}$ at the 1 month survival time disappeared over the next 3 months. We infer that many HVC neurons generated in the adult zebra finch have a life span of $<4$ months. This pattern of survival is similar to, but of greater magnitude than, that reported for HVC neurons formed in May in adult canaries (Nottebohm et al., 1994). However, there was no similar reduction in labeled neuron number over this interval in deafened birds. The net result was that, by the 4 month survival time, the number of $\left[{ }^{3} \mathrm{H}\right]$-labeled HVC neurons was no different between deafened and control birds.

We also found that deafening had no effect on HVC volume or neuron number. These results compliment and extend previous work in which deafening in juvenile male zebra finches did not impede developmental increases in HVC size or cell number (Burek et al., 1991). Collectively, our results show that deafening in adulthood influences the dynamics of neuronal replacement without altering total neuron number.

It is unlikely that deafening simply delayed the migration of new HVC neurons. In other systems, the timetable for postnatal neuronal migration is not altered by sensory deprivation (FrazierCierpial and Brunjes, 1989). Moreover, previous work has shown that new neurons arrive in $\mathrm{HVC}$ and have begun to differentiate as soon as 8-12 d after their formation (Burek et al., 1991; Kirn et al., 1999). The dramatic differences in labeled cell number between deafened and control birds at the 1 month survival time suggest another mechanism.

Postnatal sensory deprivation is known to influence the early survival of newly generated olfactory neurons (Frazier-Cierpial and Brunjes, 1989). If deafening augments the death of HVC neurons in adult zebra finches, this could account for our 1 month survival results. However, our results also show that there was actually less $\left[{ }^{3} \mathrm{H}\right]$-labeled neuron loss in deafened birds compared with controls between the 1 and 4 month survivals. This plus the absence of any overall differences in HVC neuron number between deafened and control birds suggest that deafening did not simply augment the death of adult-formed vocal control neurons. However, we cannot rule out the possibility that two types of $\mathrm{HVC}$ neurons are formed in adulthood that differ in life span and sensitivity to auditory input. If only a short-lived cell type is sensitive to auditory input, then increases in the death of these cells in deafened birds could account for our $\left[{ }^{3} \mathrm{H}\right]$ thymidine results.

We propose a third scenario, which relies on fewer precedents; deafening reduces the number of new HVC neurons added (by 


\begin{tabular}{|c|c|c|c|c|c|}
\hline & {$\left[{ }^{3} \mathrm{H}\right]$ neurons } & {$\left[{ }^{3} \mathrm{H}\right]+\mathrm{Fg}$ neurons } & {$\left[{ }^{3} \mathrm{H}\right]-\mathrm{Fg}$ neurons } & HVC neurons & Fg neurons \\
\hline \multicolumn{6}{|c|}{1 Month survival } \\
\hline Control & $8.83 \pm 0.31$ & $9.42 \pm 0.35$ & $8.82 \pm 0.36$ & $8.92 \pm 0.25$ & $8.12 \pm 0.20$ \\
\hline Deafened & $9.13 \pm 0.39$ & $9.11 \pm 0.61$ & $8.95 \pm 0.45$ & $8.39 \pm 0.20$ & $7.72 \pm 0.17$ \\
\hline \multicolumn{6}{|c|}{4 Month survival } \\
\hline Control & $7.34 \pm 0.15$ & $7.20 \pm 0.24$ & $7.38 \pm 0.24$ & $9.16 \pm 0.19$ & $8.14 \pm 0.12$ \\
\hline Deafened & $7.28 \pm 0.15$ & $7.44 \pm 0.21$ & $7.05 \pm 0.19$ & $8.69 \pm 0.31$ & $7.66 \pm 0.21$ \\
\hline
\end{tabular}

Average \pm SEM nuclear diameters of adult-formed HVC neurons $\left(\left[{ }^{3} \mathrm{H}\right]\right.$ neurons) became smaller between 1 and 4 month survival times in both deafened and control birds. This was true for new RA-projecting neurons, as defined by Fluoro-Gold labeling $\left(\left[{ }^{3} \mathrm{H}\right]+\mathrm{Fg}\right)$, as well as new neurons that were not Fluoro-Gold-labeled $\left(\left[{ }^{3} \mathrm{H}\right]-\mathrm{Fg} ; p<0.001\right)$. In contrast, the nuclear diameters of HVC neurons more generally and of RA-projecting HVC cells (Fg) did not change significantly over the same interval, although RA-projecting cell nuclei tended to be smaller in deafened compared with control birds at the 4 month survival time $(p=0.07)$. There were no other significant differences between control and deafened birds.

decreasing the production or survival of young neurons) and prolongs the survival of these cells once they have become incorporated and have established synaptic connections. There are precedents for variable life spans of adult-formed HVC neurons. In the canary, the number of new HVC neurons incorporated in the spring decreases by $50 \%$ between 1 and 4 months after $\left[{ }^{3} \mathrm{H}\right]$ thymidine injections. In contrast, no such reduction is observed over the same interval for neurons born in the fall (Kirn et al., 1991; Nottebohm et al., 1994). Other work in adult canaries may shed light on the present findings. Seasonal peaks in HVC neuron addition are preceded by increases in cell death (Kirn et al., 1994). Despite these dynamic changes in neuronal turnover, total HVC neuron number remains relatively stable over much of the year (Kirn et al., 1991). This has led to the notion that the number of new neurons added to HVC is constrained by the number of available incorporation sites (Kirn et al., 1994). If, in the present experiment, deafening prolonged the survival of adult-formed neurons, an indirect consequence of this might be that the number of available incorporation sites in $\mathrm{HVC}$ for subsequent neuron addition would be reduced compared with the case in control birds. In other words, deafening might slow the neuronal replacement cycle. This hypothesis would predict a decrease in HVC neuron addition after deafening, less attrition of new cells once they have become established in $\mathrm{HVC}$, and no net change in total neuron numbers, all of which were observed.

A more fine-grained temporal analysis of HVC neuronal addition and loss will be needed to fully understand how deafening affects neuronal replacement. Nevertheless, studies have shown that many steps in normal brain development are activitydependent. Of particular interest is the finding that activity suppression during development prolongs the life span of neurons that would otherwise die (Oppenheim, 1987; Oppenheim et al., 1997). Perhaps the absence of auditory activity has a similar effect on the survival and replacement of neurons born in adult birds.

Our results show that the nuclear diameters of $\left[{ }^{3} \mathrm{H}\right]$ thymidinelabeled HVC neurons, including adult-formed RA-projecting cells, decreased over time in both deafened and control birds. Adult-formed neurons also become smaller as they age in normal canaries (Kirn et al., 1991; Kirn and Nottebohm, 1993; Nottebohm et al., 1994). The reduction in nuclear diameters of $\left[{ }^{3} \mathrm{H}\right]$ thymidine-labeled neurons could be attributable to early stages of nuclear chromatin condensation, a process that is pronounced during apoptosis (Lo et al., 1995). Nuclear shrinkage among adult-formed HVC neurons occurs gradually (J. R. Kirn, unpublished observations), and there may be a continuum of nuclear alterations associated with aging and death with the shared characteristic of progressive chromatin condensation. It would be interesting to know whether within this continuum there is a threshold beyond which programmed cell death is activated. Further characterization of the early stages of nuclear shrinkage might shed light on how and why these adult-formed neurons die.

Although nuclear shrinkage was most pronounced for $\left[{ }^{3} \mathrm{H}\right]-$ labeled neurons, there was a nearly significant reduction in nuclear diameters for the general population of RA-projecting neurons in deafened birds compared with controls at 4 months survival. It would be interesting to see whether this latter trend becomes more robust at longer intervals after deafening. Much of the HVC-RA pathway is normally replaced (Kirn and Nottebohm, 1993). An overall reduction in RA-projecting neuronal nuclear size after deafening would be consistent with the hypothesis that deafening prolongs survival and decreases replacement, in effect causing an aging of HVC.

We found that deafening in adult male zebra finches resulted in progressive changes in song. These changes included altered note morphology, shortening of note duration, and lengthening of internote intervals. Although there was a trend for note durations to be shorter in deafened birds as early as the 1-monthpostoperative recording date, group differences were not statistically different until 3 months later. However, significant changes in internote intervals occurred by the 1-month-postoperative recording time. In general, these results are consistent with previous work (Nordeen and Nordeen, 1992). However, our results suggest that changes in internote interval occur sooner after deafening in adult zebra finches than previously reported. Moreover, our finding of a significant shortening of note length after deafening in adulthood is new.

We infer that alterations in song structure and neuronal replacement after deafening are both caused by the loss of audition. However, we do not know how direct this effect is. Other factors, such as singing frequency (vocal motor activity) and endocrine state, may change after deafening, and these changes might also be important in the regulation of song structure and neuronal replacement. We also do not know the extent to which our neurogenesis results are linked to song degradation after deafening. However, our results indicate that deafening has consequences for neuronal addition within the efferent motor pathway connecting HVC and RA. The addition of new neurons to this pathway, in the absence of auditory feedback, could lead to a gradual deterioration of song motor programs (Nordeen and Nordeen, 1992). It is also possible that alterations in the normal cycle of projection neuron replacement contribute to the ob- 

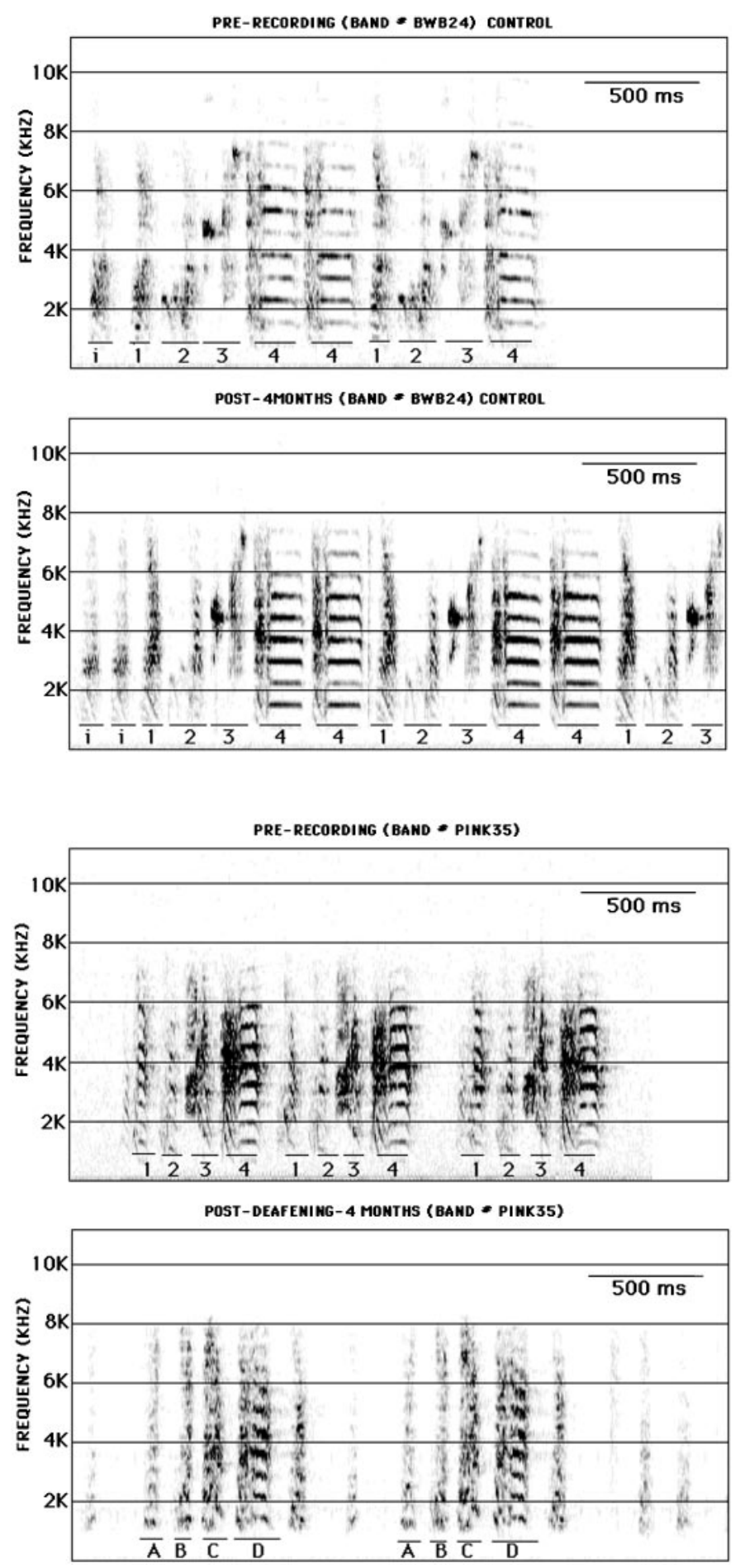

Figure 4. Sonograms from one control bird (bird BWB24; top two panels) and one deafened bird (bird PINK35; bottom two panels). Song recordings were made before deafening (PRE-RECORDING) and 4 months after deafening (POST-). Control birds were recorded at the same times. Song begins with one to several repetitions of the same short introductory note (i), followed by a regularly repeating series of distinct notes that differ by their duration, frequency envelope, and/or extent of frequency modulation (labeled 1-4 for both birds). In hearing birds, note sequences and morphology are stable from one rendition to the next as shown by the two recordings, spaced 4 months apart. In contrast, note morphology was substantially degraded in deafened birds between the two recording times. Notes 1 and 4 in the preoperative song may correspond to postoperative notes $A$ and $D$, respectively. However, notes $B$ and $C$ bear little similarity to notes 2 and 3 .
Table 2. Note duration and internote interval measurements (msec)

\begin{tabular}{lccc} 
& Prerecording & Post-1-month & Post-4-months \\
\hline Note duration & & & \\
$\quad$ Control & $155.19 \pm 19.45$ & $124.57 \pm 20.19$ & $140.54 \pm 8.37$ \\
$\quad$ Deafened & $145.66 \pm 20.76$ & $84.01 \pm 5.93$ & $70.36 \pm 6.25$ \\
Internote interval & & & \\
$\quad$ Control & $65.28 \pm 9.76$ & $74.19 \pm 5.77$ & $63.08 \pm 3.2$ \\
$\quad$ Deafened & $77.16 \pm 12.88$ & $99.40 \pm 9.35$ & $121.86 \pm 22.57$
\end{tabular}

Note duration and internote intervals were measured at three recording times. The deafened group was recorded no more than 2 weeks before surgery, 4-5 weeks after surgery (Post-1-month), and 14-16 weeks after surgery (Post-4-months). Control birds were recorded at the same times. Internote intervals significantly increased in deafened birds when compared with controls $(p=0.48$ preoperatively; $p=0.05$ at 1 month and $p=0.06$ at 4 months). Note that durations in deafened birds decreased significantly over time when compared with control birds $(p=0.75$ preoperatively; $p=0.09$ at 1 month and $p=0.003$ at 4 months).

served behavioral deficits. In particular, a delay in the death of adult-formed neurons and a matching reduction in replacement, if maintained over time, could have significant behavioral consequences.

Adult neuronal turnover may permit a rejuvenation of circuits that would otherwise be limited in their capacity to acquire and store new information (Nottebohm, 1989; Alvarez-Buylla and Kirn, 1997). Although the emphasis in the past has been placed on the relationship between neuronal replacement and learning, this rejuvenation process may also have a more basic function: preserving information regardless of whether that information is old or new, learned or unlearned. Perhaps replaceable neurons become less reliable for encoding and transmitting information as they age. If true, then manipulations that artificially prolong the life span of such cells and decrease their replacement should be associated with a compromise in function. Neuronal replacement in the adult avian brain may be a good model for addressing these issues.

\section{REFERENCES}

Alvarez-Buylla A, Kirn JR (1997) Birth, migration, incorporation, and death of vocal control neurons in adult songbirds. J Neurobiol 33:585-601.

Alvarez-Buylla A, Nottebohm F (1988) Migration of young neurons in adult avian brain. Nature 335:353-354.

Alvarez-Buylla A, Vicario DS (1988) Simple microcomputer system for mapping tissue sections with the light microscope. J Neurosci Methods 25:165-173.

Alvarez-Buylla A, Kirn JR, Nottebohm F (1990a) Birth of projection neurons in adult avian brain may be related to perceptual or motor learning. Science 249:1444-1446.

Alvarez-Buylla A, Ling C-Y, Kirn JR (1990b) Cresyl violet: a red fluorescent Nissl stain. J Neurosci Methods 33:129-133.

Brenowitz EA (1991) Altered perception of species-specific song by female birds after lesions of a forebrain nucleus. Science 251:303-305.

Brenowitz EA, Margoliash D, Nordeen KW (1997) An introduction to birdsong and the avian song system. J Neurobiol 33:495-500.

Brunjes PC (1994) Unilateral naris closure and olfactory system development. Brain Res Rev 19:146-160.

Burd GD, Nottebohm F (1985) Ultrastructural characterization of synaptic terminals formed on newly generated neurons in a song control nucleus of the adult canary forebrain. J Comp Neurol. 240:143-152.

Burek MJ, Nordeen KW, Nordeen EJ (1991) Neuron loss and addition in developing zebra finch song nuclei are independent of auditory experience during song learning. J Neurobiol 22:215-223.

Clark SJ, Cynx J, Alvarez-Buylla A, O'Loughlin B, Nottebohm F (1990) On variables that affect estimates of the true sizes and densities of radioactively labeled cell nuclei. J Comp Neurol. 301:114-122.

Clayton DF, Alvarez-Buylla A (1989) In situ hybridization using PEG- 
embedded tissue and riboprobes: increased cellular detail coupled with high sensitivity. J Histochem Cytochem 37:389-393.

Clayton NS, Krebs JR (1994) Hippocampal growth and attrition in birds affected by experience. Proc Natl Acad Sci USA 91:7410-7414.

Doupe AJ, Konishi M (1991) Song-selective auditory circuits in the vocal control system of the zebra finch. Proc Natl Acad Sci USA 88:11339-11343.

Eriksson PS, Perfilieva E, Bjork-Eriksson T, Alborn AM, Nordborg C, Peterson DA, Gage FH (1998) Neurogenesis in the adult human hippocampus. Nat Med 4:1313-1317.

Frazier-Cierpial L, Brunjes PC (1989) Early postnatal cellular proliferation and survival in the olfactory bulb and rostral migratory stream of normal and unilaterally odor-deprived rats. J Comp Neurol. 289:481-492.

Goldman SA (1998) Adult neurogenesis: from canaries to the clinic. J Neurobiol 36:267-286.

Goldman SA, Nottebohm F (1983) Neuronal production, migration, and differentiation in a vocal control nucleus of the adult female canary brain. Proc Natl Acad Sci USA 80:2390-2394.

Gould E, Beylin A, Tanapat P, Reeves A, Shors TJ (1999) Learning enhances adult neurogenesis in the hippocampal formation. Nat Neurosci 2:260-265.

Hall MF (1962) Evolutionary aspects of estrildid song. Symp Zool Soc Lond 8:37-55.

Kirn JR, Nottebohm F (1993) Direct evidence for loss and replacement of projection neurons in adult canary brain. J Neurosci 13:1654-1663.

Kirn JR, Schwabl H (1997) Photoperiod regulation of neuron death in adult canary. J Neurobiol 33:223-231.

Kirn JR, Alvarez-Buylla A, Nottebohm F (1991) Production and survival of projection neurons in a forebrain vocal center of adult male canaries. J Neurosci 11:1756-1762.

Kirn JR, O'Loughlin B, Kasparian S, Nottebohm F (1994) Cell death and neuronal recruitment in the high vocal center of adult male canaries are temporally related to changes in song. Proc Natl Acad Sci USA 91:7844-7848.

Kirn JR, Fishman Y, Sasportas K, Alvarez-Buylla A, Nottebohm F (1999) The fate of new neurons in adult canary high vocal center during the first 30 days after their formation. J Comp Neurol 411:487-494.

Konishi M (1964) Effects of deafening on song development in two species of juncos. Condor 66:85-102.

Lo AC, Houenou LJ, Oppenheim RW (1995) Apoptosis in the nervous system: morphological features, methods, pathology, and prevention. Arch Histol Cytol 58:139-149.

Nordeen KW, Nordeen EJ (1988) Projection neurons within a vocal motor pathway are born during song learning in zebra finches. Nature $334: 149-151$.
Nordeen KW, Nordeen EJ (1992) Auditory feedback is necessary for the maintenance of stereotyped song in adult zebra finches. Behav Neural Biol 57:58-66.

Nottebohm F (1985) Neuronal replacement in adulthood. In: Hope for a new neurology (Nottebohm F, ed), pp 143-161. New York: New York Academy of Sciences.

Nottebohm F (1989) From bird song to neurogenesis. Sci Am 260:74-79.

Nottebohm F, Stokes TM, Leonard CM (1976) Central control of song in the canary, Serinus canarius. J Comp Neurol 165:457-486.

Nottebohm F, O'Loughlin B, Gould K, Yohay K, Alvarez-Buylla A (1994) The life span of new neurons in a song control nucleus of the adult canary brain depends on time of year when these cells are born. Proc Natl Acad Sci USA 91:7849-7853.

Oppenheim RW (1987) Muscle activity and motor neuron death in the spinal cord of the chick embryo. Ciba Found Symp 126:96-112.

Oppenheim RW, Prevette D, Houenou LJ, Pincon-Raymond M, Dimitriadou V, Donevan A, O'Donovan M, Wenner P, Mckemy DD, Allen PD (1997) Neuromuscular development in the avian paralytic mutant crooked neck dwarf $(\mathrm{cn} / \mathrm{cn})$ : further evidence for the role of neuromuscular activity in motoneuron survival. J Comp Neurol 381:353-372.

Paton JA, Nottebohm F (1984) Neurons generated in the adult brain are recruited into functional circuits. Science 225:1046-1048.

Price PH (1979) Developmental determinants of structure in zebra finch song. J Comp Physiol Psychol 93:260-277.

Sidman RL (1970) Autoradiographic methods and principles for study of the nervous system with thymidine-H3. In: Contemporary research methods in neuroanatomy (Ebbesson S, Nauta WJH, eds), pp 252-273. Springfield, IL: Thomas.

Simpson HB, Vicario DS (1990) Brain pathways for learned and unlearned vocalizations differ in zebra finches. J Neurosci 10:1541-1556.

Smithson K, MacVicar B, Hatton G (1983) Polyethylene glycol embedding: a technique compatible with immunocytochemistry, enzyme histochemistry, histofluorescence and intracellular staining. J Neurosci Methods 7:27-41.

Sossinka R, Bohner J (1980) Song types in the zebra finch Poephila guttata castanotis. Z Tierpsychol 53:123-132.

van Praag H, Kempermann G, Gage FH (1999) Running increases cell proliferation and neurogenesis in the adult mouse dentate gyrus. Nat Neurosci 2:266-270.

Vicario DS (1994) Motor mechanisms relevant to auditory-vocal interactions in songbirds. Brain Behav Evol 44:265-278.

Vicario DS, Simpson HB (1988) Control of syringeal muscles in nucleus RA of zebra finches. Soc Neurosci Abstr 14:89.

Vicario DS, Yohay KH (1993) Song-selective auditory input to a forebrain vocal control nucleus in the zebra finch. J Neurobiol 24:488-505. 